\title{
Insulin therapy in the hospital setting: a time for a change?
}

\author{
Ada Maffettone, ${ }^{1}$ Massimo Rinaldi, ${ }^{1}$ Luigi Ussano, ${ }^{1}$ Andrea Fontanella ${ }^{2}$ \\ ${ }^{1}$ Cardiovascular and Metabolic Medicine Unit, Monaldi Hospital, Napoli; ${ }^{2}$ Department of Medicine and Emergency, Buon \\ Consiglio Fatebenefratelli Hospital, Napoli, Italy
}

\begin{abstract}
The number of people with diabetes mellitus worldwide is expected to be more than double from 171 million in 2000 to 366 million in 2030. Approximately $25 \%$ of all hospital inpatient days are affected by diabetes. In Italy there are more than 12,000 hospitalizations excesses for 100,000 people per year, with a huge economic impact. Ever since its discovery in the $1920 \mathrm{~s}$, insulin has been the milestone of type 1 diabetes treatment and its use is increasingly necessary for the successful management of type 2 diabetes. Often patients believe that injecting insulin can be painful, inconvenient and embarrassing; generally they are afraid of gaining weight and of hypoglycemia. On the other side, physician's concerns regarding insulin administration include potential dosing errors and patient non-compliance. Ever since its discovery in the mid-1920s, insulin was administered subcutaneously using a vial and syringe. In 1985 the first pen device was launched. Currently disposable insulin pens are the most used and preferred by patients in the daily use, but are not routinely used for diabetic inpatients. In this paper we will focus on the pros and cons of insulin administration with pens in the hospital setting.
\end{abstract}

\section{Introduction}

The number of people with diabetes mellitus (DM) worldwide is expected to be more than double from 171 million in 2000 to 366 million in $2030 .{ }^{1}$ The largest component (50\%) of overall costs related to diabetes care is attributed to expenditures from hospital in-patient care. ${ }^{2,3}$ The prevalence of diabetes among hospitalized patients has been conservatively estimated in $12 \%$ to $26 \%$ of adult patients and it can reach $75 \%$ in Cardiology Emergency Units. ${ }^{4}$

Correspondence: Ada Maffettone, Cardiovascular and Metabolic Medicine Unit, Monaldi Hospital, AORN Ospedali dei Colli, via L. Bianchi, 80131 Napoli, Italy.

Tel.: +39.081.7062685 - Fax: +39.081.7062577.

E-mail: adamaff@hotmail.com; ada.maffettone@ospedalideicolli.it

Key words: Diabetes mellitus; insulin therapy; insulin pen device; patient' adherence; diabetes costs.

Acknowledgements: the publication of this article is realized with the collaboration of Airon Communication and supported by a non-conditioning contribution of Novo Nordisk.

Received for publication: 15 December 2014.

Revision received: 27 July 2015.

Accepted for publication: 27 July 2015.

This work is licensed under a Creative Commons Attribution NonCommercial 4.0 License (CC BY-NC 4.0).

(C) Copyright A. Maffettone et al., 2016

Licensee PAGEPress, Italy

Italian Journal of Medicine 2016; 10:23-28

doi:10.4081/itjm.2016.576
Ever since its discovery in the 1920s, insulin has been the milestone of type 1 diabetes treatment and its use is increasingly necessary for the successful management of type 2 diabetes. Many large-scale, prospective studies have demonstrated the pivotal importance of insulin therapy in the achievement of tight glycemic control and, thus, in reducing the risk of development or progression of diabetic complications in both type 1 and type 2 diabetes. ${ }^{5,6}$ Evidence supports that direct medical costs associated with treatment of type 2 diabetes are significantly higher for people with poor glycemic control as compared to those who have optimal glycemic control. ${ }^{7}$ Despite the demonstrated efficacy of insulin therapy in achieving and maintaining glycemic control, there is often reluctance from both physicians and patients to initiate this treatment. ${ }^{8}$ Why does this happen? Often patients believe that injecting insulin can be painful, inconvenient and embarrassing; generally they are afraid of gaining weight and of hypoglycemia. On the other side, physician's concerns regarding insulin administration include potential dosing errors and scarce patient' adherence.

\section{Insulin therapy}

Ever since its discovery in the mid-1920s, insulin was administered subcutaneously using a vial and syringe and this was the only available way of administration up until the mid-1980s. In 1985 the first pen device was launched. Pen devices consisting of an insulin cartridge and needle in one device were subsequently developed improving the ease of insulin administration. Insulin initiation has become easier using insulin analogues associated with pens and these 
devices are currently on the market for both rapid insulin analogues (aspart, glulisine, lispro) and for basal insulin analogues (degludec, detemir, glargine).

Concerning in-patients therapy, it is well known the direct correlation between in-patient hyperglycemia and mortality. Hyperglycemia is common in the hospital setting and it correlates with poor patient outcomes. The treatment of hyperglycemia in the hospital setting is a challenge for clinicians because in-patients often have fluid imbalance, unstable nutritional status, are administered hyperglycemic drugs, indeed are in critical state with life-threatening situations.

In the critical setting insulin should be intravenously administered while, in non-critical setting the subcutaneous way is used with basal, nutritional and correction doses. In the recent past, insulin was administered with vials and syringes, now clinicians have a few strings on their bow: insulin pens.

\section{Insulin pen therapy adherence}

Currently disposable insulin pens are the most used and preferred by patients at home. Pen characteristics include easy-to-dial up and down dosing of one and a half unit increments with audible clicks, large and clear mechanical or digital dose displays and confirmation that the dose has been delivered. Pens are also light to carry and slim and some have color-coding to identify the insulin used. Usually pen devices are used almost totally for daily therapy in normal life, while in hospital insulin vials and syringe are almost everywhere adopted; this situation often bewilders patients who have their usually at home therapy modified once in the hospital. Further, for naïve diabetic in-patients, the peninsulin might represent a newer and safer way to administer insulin respect to syringe.

In a randomized clinical trial by Korytkowsky $74 \%$ of patients of the study, which included patients with both types 1 and $2 \mathrm{DM}$, expressed a preference in continuing using the pen rather than continuing with the vial/syringe. The use of the traditional vial and syringe for the delivery of insulin therapy has several disadvantages, including anxiety about self-injection, fear of injection, a dosing schedule, difficulty of transportation, training time, sometimes social embarrassment, all of which may negatively affect patients' adherence to therapy. ${ }^{9}$ To help overcome these barriers to insulin treatment, the delivery of insulin should be simple and accurate, thereby encouraging patient compliance and minimizing dosing error. With the insulin cartridge and syringe combined in a single unit, pen devices have been reported to improve dosing accuracy, increase meal time flexibility and convenience of insulin delivery, and have positive effects on patient preference and treatment satisfaction. Additional advantages of prefilled insulin pens include improved patient's self-confidence, ease of training and greater stability of the device during injection (handling). By lowering injection pain, the increasing use of insulin pens rather than traditional insulin delivery devices may lead to better health-related quality of life ${ }^{10,11}$ (Figure 1).

A review by Brunton ${ }^{12}$ suggests that patients are more confident in the use of pen devices compared with vial/syringe. Some insulin injection pens are prefilled and have integral insulin cartridges, some have a refill system that allows to re-use the pen for months or years. From a treatment compliance perspective, simplicity of use is particularly important for older patients (aged $>65$ years) who have difficulty in handling injection devices or for individuals who are too busy or physically active to devote much attention to their injection devices. Indeed, all insulin pens demonstrated the highly accurate delivery of insulin doses in everyday practice.

The past criticism on the use of these pens and their impact on the ecological system are now outdated: currently pens are made with biodegradable materials. ${ }^{13}$

Previous clinical studies showed that patients using the vial/syringe method may have more risk of drawing and injecting an inaccurate dose of insulin: Kesson and Bailie ${ }^{14}$ found a relative error of $\sim 19 \%$ in the accuracy of the doses performed. Insulin pens present some positive aspects even in hospitalized patients (Table 1). The principal positive aspect is, indeed, the greater satisfaction among patients, physicians and nurses. In a paper by Davis, 96 patients were recruited from two general medical-surgical units from July 2005 to May 2006; they completed a survey regarding satisfaction with the method used to administer insulin before discharge. Increased patient satisfaction and continuation of the method of insulin administration used in the hospital at home were reported by patients who received insulin pens compared with patients who received conventional vials and syringes during hospitalization. ${ }^{15}$ Furthermore, patient's confidence and later adherence, improved with insulin pens. ${ }^{16}$ The hospitalization might become an

\section{COMPLIANCE TO INSULIN THERAPY}

Advantages of the use of pre-filled disposable pens $v s$ therapy with syringes and vials

- Improved accuracy in insulin dosing

- More user-friendly for the elderly and their care-givers

- Use of very low doses of insulin

- Less impact on social life and ease of transportation

Figure 1. Advantages of insulin pen use. 
education period for the naïve insulin treated patient: hospitalization, indeed, may provide an opportunity to learn how to manage insulin therapy, to overcome the fear of puncture, thus gaining self-confidence with this injectable drug.

\section{Safety profile of pen devices}

There are some problems of safety concerning the use of insulin pens in hospitals. There is a risk of contamination if nurses use a pen cartridge as a multi-dose vial, withdrawing insulin from the vial with a syringe for administration to a single patient or multiple patients. The improper sharing of pens among hospitalized patients, thus leading to pathogen infections, has been reported despite efforts to warn health care professionals about the danger. The Center for Disease Control and Prevention (CDC) in USA has become increasingly concerned about the risks of transmitting hepatitis B virus and other infectious diseases during insulin administration. CDC is alerting all persons who assist others with insulin administration that: i) insulin pen and vial+syringe are both for single-patient-use only and should never be used for more than one person; ii) multi-dose vials of insulin should be dedicated to a single person whenever possible; iii) insulin can be administered using an insulin pen that is designed for reuse on a single patient. It can also be administered using a needle and syringe after drawing up contents from an insulin vial; iv) insulin pens are pen-shaped injector devices for insulin that are intended for use by a single person. ${ }^{17}$

Furthermore, needlestick injuries can occur in the daily practice among health-related personnel. It is estimated that the accidental puncture is the most common injury in hospitals, after traumatic accidents. ${ }^{18}$ In particular, a survey conducted by AIRESPSA (Asso- ciazione Italiana Responsabili Servizi Prevenzione e Protezione Aziende Sanitarie) in 2002 and in 2004 showed that about $40 \%$ of all injuries in hospital personnel are due to exposure to biological risk (percutaneous and mucocutaneous) and $70-80 \%$ of these injuries are due to injuries with needles and other sharp devices used. So it is important, among hospital personnel, the use of safety devices for insulin administration. Besides, on June 1, 2010 the European Community published Directive 2010/32; ${ }^{19}$ it requires that all Member States must implement within three years a comprehensive strategy to prevent exposure, for health-related employees, to punctures through needle or sharp injury devices, including the adoption of security safeguards based on risk assessment. ${ }^{20}$ This Directive 2010/32 provides that in all the activities in which sharp medical devices are used, formal assessments of the risks must be conducted and that, wherever there is a risk of injury or infection, it must be eliminated by personnel training, by improvement of work practices and the introduction of medical devices with safety mechanisms. For insulin injections the use of safety devices is mandatory. The work of Ward ${ }^{21}$ evaluated the impact of a hospital initiative to reduce staff needle-stick injuries and overall insulin costs by switching from insulin vials to insulin pens for treatment of in-patients. There was one staff needlestick injury, compared with five injuries during the designated pre implementation period. Insulin expenses were reduced by approximately $\$ 60,000$ over six months, primarily through the switch from vials of long-acting insulin products to the insulin pen. Poor visualization may occur during insulin pen use, leading to needle-stick injuries or causing insulin to leak from the injection site. This event can occur when clinicians do not maintain, during injection, a 90 degree angle with skin surface or when there is a scarce vi-

Table 1. Insulin therapy in the hospital setting.

\begin{tabular}{|c|c|c|c|}
\hline \multicolumn{2}{|c|}{ Vials + Syringes } & \multicolumn{2}{|c|}{ Disposable pens } \\
\hline Pros & Cons & Pros & Cons \\
\hline Minor costs & $\begin{array}{c}\text { Waste of used insulin vials in } \\
\text { wards with lesser diabetes } \\
\text { prevalence }\end{array}$ & $\begin{array}{l}\text { Less insulin waste for average } \\
\text { insulin doses and LOS } \\
\text { of about } 7 \text { days }\end{array}$ & $\begin{array}{l}\text { Potentially more expensive } \\
\text { for short LOS in hospital }\end{array}$ \\
\hline $\begin{array}{c}\text { Possibility of insulin } \\
\text { sampling for intravenous } \\
\text { use from the vial }\end{array}$ & More painful injection & $\begin{array}{l}\text { Less painful injections and more } \\
\text { satisfaction to therapy }\end{array}$ & $\begin{array}{l}\text { No insulin sampling from vials } \\
\text { (possibility to use only one } \\
\text { pen in wards for insulin sampling } \\
\text { from pen cartridge) }\end{array}$ \\
\hline \multirow[t]{2}{*}{$\begin{array}{c}\text { Ease of therapy: } \\
\text { one vial for more } \\
\text { patients simultaneously }\end{array}$} & Possible dosage errors & $\begin{array}{c}\text { More dosage precision } \\
\text { and less errors, less hypoglycemia } \\
\text { episodes }\end{array}$ & $\begin{array}{l}\text { Need of pen personalization } \\
\text { (one pen, one patient) }\end{array}$ \\
\hline & $\begin{array}{l}\text { No education to insulin } \\
\text { self-therapy at home }\end{array}$ & $\begin{array}{l}\text { Self-education for patients } \\
\text { to insulin therapy }\end{array}$ & \\
\hline
\end{tabular}

LOS, length of stay. 
sualization of site of injection. Recently new needles arrived on the market: they present a cover that automatically deploys after injection not needing the recapping and thus eliminating the risk of injuries. Similar labeling and/or similar name of different pen types could lead to errors. The Institute for Safe Medical Practices (ISMP) recommends institutions to take initiatives in improving patient and staff safety to limit the variety of insulin pens available in an institution as a way to prevent mix-ups and promote staff education and competency with use of the devices. ${ }^{22}$ In order to avoid all these negative aspects of misuse of insulin pens for in-patients, strategies for ensuring safe insulin must be pursued. Hospitals must develop proper strategies in implementing policies and procedures through staff educations. It is mandatory to use a single pen for each patient: it seems fundamental to bar-code the pen (maybe by hospital Pharmacy) with the name and date of birth of patient at the admission in hospital. The American Society of Health-System Pharmacists (ASHP) Foundation recommends newer technology solutions avoiding the shared use of insulin pens. They include labelling personally with name and date of birth the insulin pen not obscuring the drug name and encourage the electronic insulin order to the hospital pharmacy (for example barcodes). Furthermore, it seems important to identify a specific storage place for insulin pens and for new and unused pens and cartridges. Much importance must be given to education of health-related personnel, giving adequate information on prescribing, storing, dispensing and administering insulin through pens. It seems particularly helpful to use pc screen savers, reminders, posters in hospitals for health-related staff. The insulin pen could be given at discharge at the patient so that no insulin waste would occur. It would be very important to assure and encourage hospitalterritory adequate clinical pathways: these pathways would avoid insulin wastage of $1000 \mathrm{IU} /$ insulin per bottle, since - as said before - usually disposable insulin pens are preferred by diabetic patients in their daily domestic routine.

Another important aspect to consider is the health personnel's continuous updating. The improvements in staff safety previously achieved concerning proper use of insulin pens, must be maintained by continuous training of newly hired staff by the diabetes educators staff. With regard to patient's safety, the pens dispensed must be patient specific, and nurses have to be trained on the dangers of using pen cartridges as multi-dose vials for individual or multiple patients. We believe that the use of some tools of clinical governance i.e., audit (as a quality of care improvement tool) should be promoted among health staffs. Cyclical diabetes care providers' meetings on insulin pen use and misuse for in-patients should be routinely performed.

\section{The Health-Economic impact of the insulin pen therapy}

Concerning the economic aspect of insulin pen use, there are no studies, at the moment, in Europe focused on this particular aspect. There have been some studies evaluating treatment adherence, healthcare resource utilization and the associated costs of therapy conversion from vial/syringe to insulin pen. In the paper by Lee et $a l .{ }^{23}$ performed in the USA, the economic evaluation of insulin pens $v s$ cartridges showed that the use of insulin pens significantly improved medication adherence, reduced hypoglycemic events and lowered treatment costs. In this study the total annual costs of insulin therapy (including the costs of insulin and delivery devices) were reduced by 1600 USD per patient who switched from vial and syringe to pen, the hypoglycemia costs were reduced by 800 USD and the costs of diabetes-attributable healthcare were reduced by 600 USD. In a study by Niskanen, ${ }^{24} 486$ adult patients with type 2 diabetes, with no previous experience of insulin pens, switched from human insulin or insulin analogue administered via vial and syringe to pen. The hypoglycemic events were reduced by two-thirds after the vial/syringe and pen switch. The switch to pen also reduced costs of mean all-cause annual treatment (emergency department costs and annual visits, outpatient visit costs, hospitalization costs, hospital length of stay, physician visit costs, pharmacy costs) (by $\$ 1748 /$ patient), hypoglycemia-attributable costs ( $\$ 908 /$ patient) and other diabetes-attributable costs (\$643/patient). An observational study on 1622 patients receiving insulin injections who switched from a traditional syringe to an insulin pen found that the pen device was associated with a statistically significant improvement $(\mathrm{P}<0.05)$ in hypoglycemia or hyperglycemia status and all other items assessed on the diabetes treatment satisfaction questionnaire. ${ }^{25} \mathrm{~A}$ recent survey by Pugni performed in 8 different wards of a Northern Italy hospital showed that nurses found multi-dose pens more satisfying and user friendly than syringes in both insulin preparation and administration. Furthermore, they found the use of prefilled pens more time-saving, safe and satisfactory than syringes. ${ }^{26}$

It seems clear that insulin pen devices offer greater convenience, flexibility, treatment satisfaction, ease of use, perceived dosing accuracy, self-efficacy, less pain and administration time compared to vial and syringe. These findings support the idea that insulin pen device use can potentially improve adherence to insulin therapy regimens. Diabetes care providers and patients can all contribute in reducing barriers associated with conventional insulin therapy by incorporating well-accepted insulin delivery device into diabetes management programs, practice, and protocols. This seems particularly suitable for naïve diabetic in-patients who 
have insulin administered for the first time in their life.

In a randomized, open-label, crossover study of 121 patients with diabetes (107 with type 2 diabetes), a questionnaire revealed that $74 \%$ of patients considered an insulin analogue pen device easier to use than conventional syringes, and $85 \%$ indicated that the insulin-dose scale was easier to read. ${ }^{9}$ Ease of use could be particularly important for elderly patients who have difficulties with accurate self-dosing using a vial and syringe. ${ }^{27,28}$ One trial of 79 elderly patients with diabetes ( 77 with type 2 diabetes) and visual or motor disabilities who had difficulty for insulin administration via the vial and syringe method, found that $53 \%$ of patients could independently use a prefilled insulin injection device, compared with only $20 \%$ who could independently use the vial and syringe. ${ }^{29}$

Although previously published total pharmacy costs for insulin analogue pen devices are higher than those for vials of human insulin or insulin analogues, the maintenance of insulin costs may be due to the fact that improvements in adherence and outcomes may have allowed for lower daily doses of insulin. Also, with the pen devices, there would be less insulin wastage due to the expiration of open vials. ${ }^{30}$

The economic aspects concerning the use of insulin pen devices in the hospital setting are challenging, need deep knowledge of the issue and must consider different aspects: i) in the hospital setting, not in all wards the insulin vial is completely used within a month after its opening (thus leaving insulin not completely consumed); ii) we must consider the option of giving to the patient, at discharge, the insulin pen device which could be used at home for a month after its opening (in Italy Decree-Law 219/2006 and Decree-Law 833/1978 oblige hospital pharmacists to give to every single patient, at discharge, a new and whole insulin pen box); ;1,32 iii) we must consider that usually all the patients use insulin pen devices at home; using insulin vials at discharge could confuse patients and their therapy adherence; iv) in the hospital setting, insulin vials seem less expensive than insulin pen devices, but we must take into account the costs attributable to safety insulin syringes $v s$ insulin pens safety needles and the greater amount of waste material deriving from used safety syringes to be eliminated; v) last, but not least, the use in hospitals of safety needles on both sides of the needle seems ethically correct; the initial high economical cost of these safety devices for in-patients could obviously be amortized, later, by a reduction in needle stick injuries and direct and indirect correlated costs.

In a study of Medicaid data, patients who initiated insulin therapy with a pen device had significantly lower insulin prescription costs than those who initiated insulin therapy via a vial and syringe (\$6123 versus $\$ 7466, \mathrm{P}<0.05) .{ }^{33}$ In the USA the use of insulin pens in hospitals is more cost-effective than vial-and-syringe delivery forms. Insulin pens have been pilot-tested in $30 \%$ of hospitals, and their use is estimated to provide an average cost savings of $\$ 36$ per patient per hospital stay. ${ }^{34}$ Pens may provide increased accuracy with small insulin doses, especially with the administration of $<5$ units. In Europe, at the moment, there are no studies available concerning this particular aspect, even if the topic seems appealing and interesting.

\section{Conclusions}

The administration of insulin with a pen device is preferred by patients and health-related staff $v s$ administration with a vial and syringe, and the preference is associated with improved adherence to therapy, decreased incidence of hypoglycemic episodes and reduction in associated health care resource utilization and costs. If higher levels of adherence translate into improved glycemic control, the greatest reductions in overall health care costs from switching from vials and syringes to an insulin analogue pen device may come from a reduction in the long-term complications of diabetes and the considerable associated costs even in the hospital setting where personnel's and patients' safety must be constantly pursued.

\section{References}

1. Wild S, Roglic G, Green A, et al. Global prevalence of diabetes: estimates for the year 2000 and projections for 2030. Diabetes Care 2004;27:1047-53.

2. Centers for Disease Control and Prevention. National Diabetes Fact Sheet, United States 2005. Available from: http://stacks.cdc.gov/view/cdc/7054/

3. Harris MI, Flegal KM, Cowie CC, et al. Prevalence of diabetes, impaired fasting glucose, and impaired glucose tolerance in US adults. The Third National Health and Nutrition Examination Survey (NHANES) 1988-1994. Diabetes Care 1998;21:518-24.

4. Brown J6, Pedula KL, Bakst AW. The progressive cost of complications in type 2 diabetes mellitus. Arch Intern Med 1999;159:1873-80.

5. UK Prospective Diabetes Study (UKPDS) Group. Intensive blood-glucose control with sulphonylureas or insulin compared with conventional treatment and risk of complications in patients with type 2 diabetes (UKPDS 33) [published correction appears in Lancet 1999;354: 602]. Lancet 1998;352:837-53.

6. The Diabetes Control and Complications Trial Research Group. The effect of intensive treatment of diabetes on the development and progression of long-term complications in insulin-dependent diabetes mellitus. N Eng $\mathrm{J}$ Med 1993;329:977-86.

7. Wagner EH, Sandhu N, Newton KM, et al. Effect of improved glycemic control on health care costs and utilization. JAMA 2001;285:182-9.

8. Korytkowski M, Niskanen L, Asakura T. FlexPen: ad- 
dressing issues of confidence and convenience in insulin delivery. Clin Ther 2005;27:S89-S100.

9. Korytkowski M, Bell D, Jacobsen C, et al. A multicenter, randomized, open label, comparative, two-period crossover trial of preference, efficacy, and safety profiles of a prefilled, disposable pen and conventional vial/syringe for insulin injection in patients with type I or 2 diabetes mellitus. Clin Ther 2003;25:2836-48.

10. Niskanen L, Jensen LE, Rastam J, et al. Randomized, multinational, open-label, 2-period, crossover comparison of biphasic insulin aspart 30 and biphasic insulin lispro 25 and pen devices in adult patients with type 2 diabetes mellitus. Clin Ther 2004;26:531-40.

11. Newman KD, Weaver MT. Insulin measurement and preparation among diabetic patients at a county hospital. Nurse Pract 1994;19:44-5, 48.

12. Brunton S. Initiating insulin therapy in type 2 diabetes: benefits of insulin analogs and insulin pens. Diabetes Technol Ther 2008;10:247-56.

13. Pfützner A. FlexPen for the delivery of insulin: accuracy, injection force and patient preference. Exp Rev Med Devices 2009;6:115-23.

14. Kesson CM, Bailie GR. Do diabetic patients inject accurate doses of insulin? Diabetes Care 1981;4:333.

15. Davis EM, Christensen CM, Nystrom KK, et al. Patient satisfaction and costs associated with insulin administered by pen device or syringe during hospitalization. Am J Health Syst Pharm 2008;65:1347-57.

16. Cobaugh DJ, Maynard G, Cooper L, et al. Enhancing insulin-use safety in hospitals: practical recommendations from ASHP Foundation expert consensus panel. Am J Health Syst Pharm 2013;70:1404.

17. Centers for Disease Control and Prevention. Infection prevention during blood glucose monitoring and insulin administration; last updated: May 2, 2012. Available from: http://www.cdc.gov/injectionsafety/blood-glucosemonitoring.html

18. Davis EM, Bebee A, Crawford LA, Destache C. Nurse satisfaction using insulin pens in hospitalized patients. Diabet Educ 2009;35:799-809.

19. European Regulation. Council Directive 2010/32/EU of 10 May 2010 implementing the Framework Agreement on prevention from sharp injuries in the hospital and healthcare sector concluded by HOSPEEM and EPSU. In: Official Journal, L 134, 1/6/2010, pp 66-72. Available from: http://eur-lex.europa.eu/legal-content/EN/ TXT/?uri=CELEX:32010L0032

20. Puro V, De Carli G, Segata A, et al. Aggiornamenti in tema di epidemiologia delle malattie infettive occupazionali trasmesse per via ematica. Ital Med Lav Erg 2010;32:235-9.

21. Ward LG, Aton SS. Impact of an interchange program to support use of insulin pens. Am J Health Syst Pharm 2011;68:1349-52.
22. Institute for Safe Medication Practices. Considering insulin pens for routine hospital use? Consider this... ; May 8, 2008. Available from: http://www.ismp.org/ Newsletters/acutecare/articles/20080508.asp

23. Lee WC, Balu S, Cobden D, et al. Medication adherence and the associated health-economic impact among patients with type 2 diabetes mellitus converting to insulin pen therapy: an analysis of third-party managed care claims data. Clin Therap 2006;28:1712-25.

24. Niskanen L. A clinical and health economic review of a prefilled insulin pen. Curr Med Res 2010;10:2431-9.

25. Albano S; Orbiter study group. Assessment of quality of treatment in insulin-treated patients with diabetes using a pre-filled insulin pen. The ORBITER Study Group. Acta Biomed 2004;75:34-9.

26. Pugni V, Babini M, Manicardi E. Indagine sulla soddisfazione del personale infermieristico nell'utilizzo di penne multidose di insulina in pazienti ricoverati in ospedale. Il Giornale di AMD 2014;17:230-47.

27. Coscelli C, Lostia S, Lunetta M, et al. Safety, efficacy, acceptability of a pre-filled insulin pen in diabetic patients over 60 years old. Diabetes Res Clin Pract 1995; 28:173-7.

28. Shelmet J, Schwartz S, Cappleman J, et al. Preference and resource utilization in elderly patients: InnoLet versus vial/syringe. Diabetes Res Clin Pract 2004;63:27-35.

29. Puxty JA, Hunter DH, Burr WA. Accuracy of insulin injection in elderly patients. Br Med J 1983;287:1762.

30. Meece J. Effect of insulin pen devices on the management of diabetes mellitus. Am J Health Syst Pharm 2008;65:1076-82.

31. Pawaskar MD, Camacho FT, Anderson RT, et al. Health care costs and medication adherence associated with initiation of insulin pen therapy in Medicaid-enrolled patients with type 2 diabetes: a retrospective database analysis. Clin Ther 2007;29:1294-305.

32. Parlamento Italiano. Decreto Legislativo 24 aprile 2006, n. 219. Attuazione della direttiva 2001/83/CE (e successive direttive di modifica) relativa ad un codice comunitario concernente i medicinali per uso umano, nonché della direttiva 2003/94/CE. GU Serie Generale, n. 142, 21/6/2006 - Suppl. Ordinario n. 153. Available from: http://www.gazzettaufficiale.it/eli/id/2006/06/21/006G0 $237 / \mathrm{sg}$

33. Ministero dellsa Salute. Legge 23 dicembre 1978, n. 833 Istituzione del servizio sanitario nazionale. GU Serie Pregressa, n. 360, 28 dicembre 1978. Available from: http://www.trovanorme.salute.gov.it/norme/dettaglio Atto?id=21035

34. Davis EM, Christensen CM, Nystrom KK, et al. Patient satisfaction and costs associated with insulin administered by pen device or syringe during hospitalization. Am J Health Syst Pharm 2008;65:1347-57. 